\title{
Extreme Wide Band MIMO Antenna System for Fifth Generation Wireless Systems
}

\author{
Haitham Alsaif \\ Electrical Engineering Department \\ College of Engineering \\ University of Hail \\ Hail, Saudi Arabia \\ hal-saif@hotmail.com,h.alsaif@uoh.edu.sa
}

\begin{abstract}
A new compact $2 \times 2$ Multiple Input Multiple Output (MIMO) antenna is presented in this paper, suitable for the new wireless communications. The proposed design also covers the complete ultra-wideband for short wireless systems. The antenna system is characterized by a super wideband covering radio frequency (RF) band starting from $2.97 \mathrm{GHz}$ to $19.82 \mathrm{GHz}$. The MIMO system contains two ship-shaped monopoles with trimmed edges. These antennas are printed on a single layer of Rogers Duroid RT5880Lz with relative permittivity $\varepsilon r=1.96$ and loss tangent $\delta$ of 0.0009 . The overall size of the MIMO system is $20 \mathrm{~mm} \times 47 \mathrm{~mm} \times 1.6 \mathrm{~mm}$. The peak-achieved gain is $8.12 \mathrm{~dB}$ with nearly omni-directional isotropic far field patterns. The design and simulation has been performed via an industrial simulation code.
\end{abstract}

\section{Keywords-5G; ultra-wide band; planar antenna}

\section{INTRODUCTION}

A dramatic increase in data rates is mandatory by the new generation wireless systems, which ga rise to challenges of the communication systems industry. Long-Term Evolution (LTE) in Fourth Generation commercial services is at the border of meeting these high data rate requests. Presently, in order to overcome such problems, the industry is launching sub- $6 \mathrm{GHz}$ for the 5th Generation mobile devices. However, it is aimed to use the current networks and then shift to higher bands or millimeter bands from $28 \mathrm{GHz}$ to $85 \mathrm{GHz}$ by the end of 2020 [14]. The present spectrum bandwidth, which is lower than $6 \mathrm{GHz}$ is not enough to meet the future requirements. Therefore, new spectrum allocations above $6 \mathrm{GHz}$ are essential in order to alleviate the existing spectrum lack which is the main motivation in introducing the $5 \mathrm{G}$ in wireless communications systems. In the last few years studies for the $5 \mathrm{G}$ have started to move up from ultra-high frequencies (UHF) (300MHz-3GHz) to new frequency bands in the microwave range, counting millimeter-wave spectrums. Henceforth, the spectrum range above $6 \mathrm{GHz}$ and $\mathrm{mm}$-wave bands are the chief bases in solving $5 \mathrm{G}$ challenges [5-9].

Different new ultra-wideband antennas with variety designs (rectangular, circular, elliptical, etc.) have been designed [513]. The designs differ in terms of parameters such as frequency bands, radiation, gain, and physical size. Some of these designs have shortages in their operating frequencies which do not include UWB set by FCC (3.1 to $10.6 \mathrm{GHz})$. The suggested planar antenna in this paper is competitive with many of the previously published designs and has a reduced structure size.

Aiming to satisfy this new challenge of intensely increasing data rates, a $2 \times 2$ MIMO antenna system is proposed. The system has been designed and simulated in order to evaluate and test its performance. MIMO antenna systems are enormously employed in wireless devices to enrich the channel capability and multipath propagation and to improve high datarates $[10-15]$.

\section{ANTENNA DESIGN}

The geometrical arrangement of the proposed MIMO antenna along with design parameters for two feeding ports UWB MIMO are shown in Figure 1. The microstrip antennas have a simple and reduced structure size, which is $24 \mathrm{~mm}$ long and $20 \mathrm{~mm}$ wide, printed on a Rogers Duroid RT5880Lz substrate with $1.6 \mathrm{~mm}$ thickness with relative permittivity $\varepsilon \mathrm{r}=1.96$ and loss tangent $\delta=0.0009$. As shown in Figure 1, the MIMO consists of two shipshape radiators with truncated edges in order to enrich the impedance matching and to improve the bandwidth up to $17 \mathrm{GHz}$ [17]. Table I illustrates he optimized values of the geometric variables. The ship-shape antennas cover a radio frequency band from $2.97 \mathrm{GHz}$ to $19.89 \mathrm{GHz}$, which includes IEEE $802.11 \mathrm{a} / \mathrm{b} / \mathrm{g} / \mathrm{n} / \mathrm{ac}$ standards and sub-6GHz $5 \mathrm{G}$ bands as well. Additionally, this compact super wide band MIMO antenna system fulfills the frequency operating regulations of the Federal Communication Commission (FCC) for UWB communication systems [16-17]. Thus, the designed system is a model candidate for use in the UWB, Wi-Fi and sub-6GHz, i.e. 5G mobile due to its very compact design and characteristics.

\section{PARAMETRIC STUDY AND SIMULATION RESULTS}

Parameter investigation and optimization have been conducted in order to discover the key parameters and to enhance the MIMO antenna's performance in terms of bandwidth, isolation, power gain, and radiation pattern. Figures 2 and 3 show the optimized reflection coefficients (S11) and (S22) in $\mathrm{dB}$ versus the operating frequency in GHz. They display the super ultra-wide bandwidth that varies from $2.97 \mathrm{GHz}$ to $19.82 \mathrm{GHz}$, which covers the whole bandwidth allocated for short wireless systems and the entire lower $5 \mathrm{G}$ 
bands. The covered bandwidth holds all bands in Europe, Japan, China, Korea, and United States. The reflection coefficient has multiple resonant frequencies of $3.48 \mathrm{GHz}$, $7.32 \mathrm{GHz}, 9.89 \mathrm{GHz}$, and $17.62 \mathrm{GHz}$. A part of the parametric optimization process for the proposed antenna system for different values of the feeding strip line width is demonstrated in Figure 4. It is observed that the greatest impedance matching is attained at a line width of $2.7 \mathrm{~mm}$.

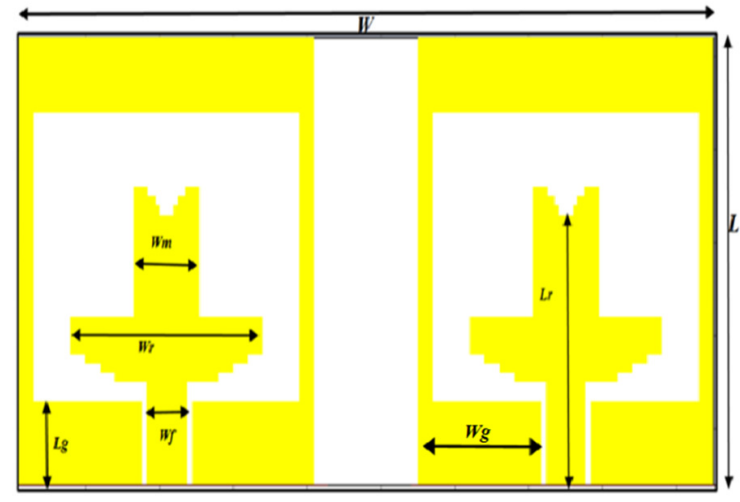

Fig. 1. Geometry of the proposed MIMO antenna

TABLE I. PARAMETERS OF THE DESIGNED $2 \times 2$ MIMO ANTENNA

\begin{tabular}{|c|c|c|c|c|c|c|c|l|}
\hline Parameter & W & L & Wg & Lg & Wr & Lr & Wf & Wm \\
\hline Value $(\mathrm{mm})$ & 45 & 20 & 8.3 & 4.5 & 13 & 17 & 2.7 & 4.5 \\
\hline
\end{tabular}

Multiple substrate materials such as FR-4 (cr=4.3), Rogers RT 5880Lz ( $\varepsilon r=1.96)$, and Polymide $(\varepsilon r=3.5)$ have been investigated for optimization purposes. The reflection coefficients S11 for these materials are plotted in Figure 5. It can be clearly noticed that the antenna's bandwidth has been optimized by using Rogers Duroid RT $58801 z$ as a substrate material and during this super wide bandwidth the reflection coefficient is lower than $-10 \mathrm{~dB}$. Figure 7 displays the normalized radiation pattern at resonant frequencies $3.35 \mathrm{GHz}$, $7.31 \mathrm{GHz}$, and $9.89 \mathrm{GHz}$ for the main perpendicular planes (elevation $(\mathrm{E})$ and azimuth $(\mathrm{H})$ ) in polar form. Generally, the presented antenna has an omni-directional radiation pattern with minor distortion at a higher part of the bandwidth as a result of the high growth in the power gain. Consequently, the proposed MIMO antenna can be inserted inside wireless systems at any position due to its radiation feature. The antenna is characterized by its high gain, which exceeds $8.12 \mathrm{dBi}$. Figure 8 displays the proposed MIMO system power gain in $\mathrm{dB}$ versus the entire operating frequency in $\mathrm{GHz}$.

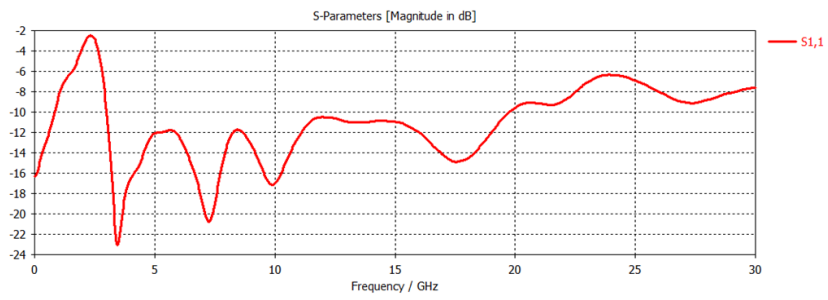

Fig. 2. Simulated reflection coefficient (S11) vs operating frequency
The key factor in MIMO performance and the major effort in designing MIMO antennas is obtaining lower transmission coefficient (S12 and S21) values between the two ports. In Figure 8 it can be observed that both antennas have well decoupled, which have S12 and S21 less than $-16 \mathrm{~dB}$ as well as good mutual coupling between the monopoles elements in the entire bandwidth.

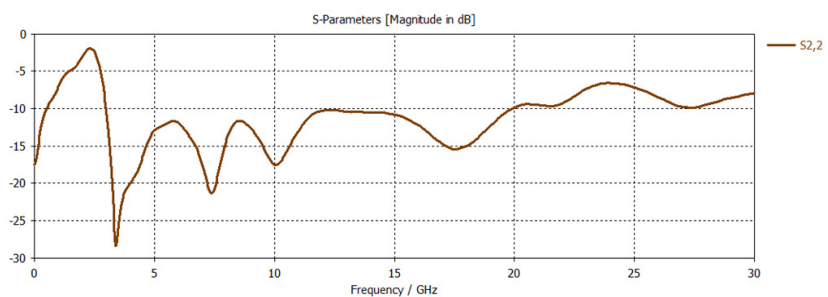

Fig. 3. Simulated reflection coefficient (S22) vs operating frequency

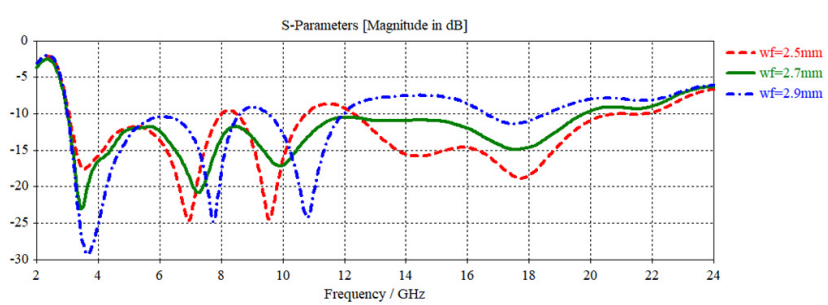

Fig. 4. Reflection coefficients for several values of feeding line width

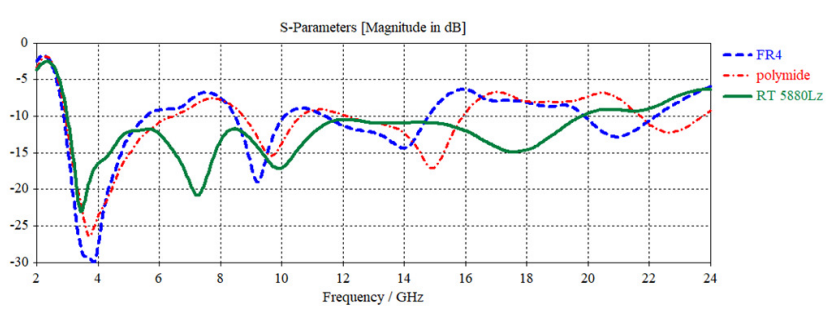

Fig. 5. Several substrate materials for the proposed MIMO antenna

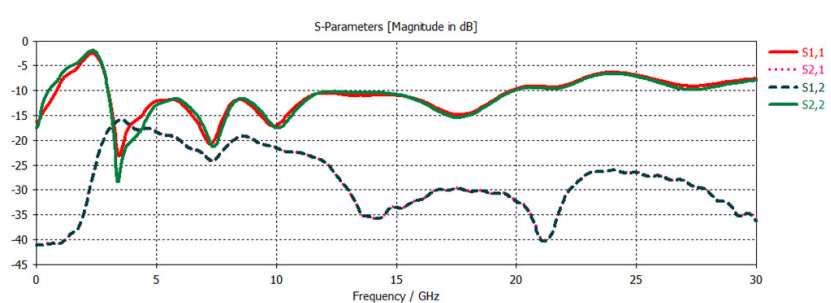

Fig. 6. Reflection and transmission coefficients for the monopole system vs operating frequency

A brief performance comparison between the proposed MIMO antenna system with similar MIMO antennas available in literature in terms of bandwidth, isolation, power gain, and structure size is presented in Table II. The Table clarifies that the suggested antenna is compact in size with extremely wide bandwidth, high power gain and isolation in comparison with similar existing antennas. 

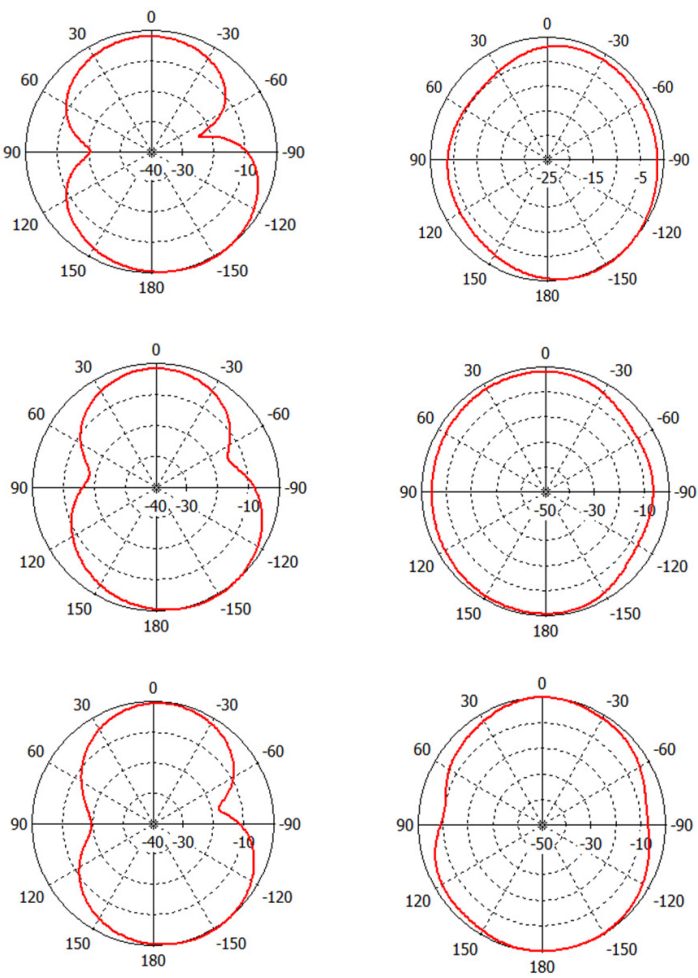

Fig. 7. Simulated power radiation pattern in polar form (elevation and azimuth planes) of the proposed MIMO antenna at $3.48 \mathrm{GHz}, 7.32 \mathrm{GHz}$ $9.89 \mathrm{GHz}$, and $17.62 \mathrm{GHz}$

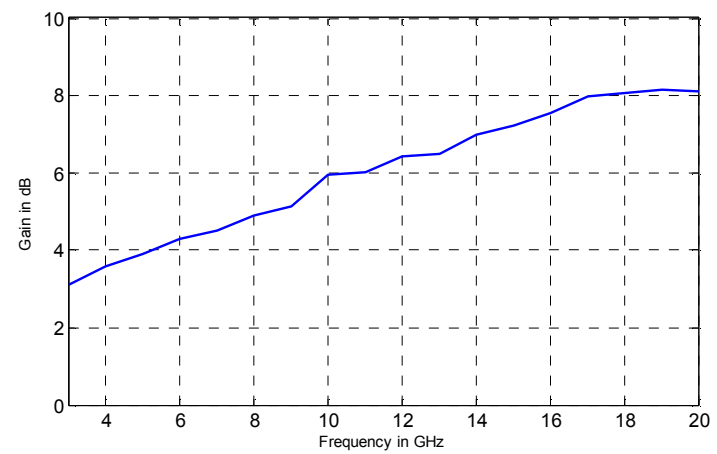

Fig. 8. Simulated power gain during the operating frequency with maximum gain of $8.12 \mathrm{~dB}$

TABLE II. PERFORMANCE COMPARISON BETWEEN THE PROPOSED ANTENNA AND PREVIOUSLY PUBLISHED DESIGNS

\begin{tabular}{|c|c|c|c|c|}
\hline Reference & $\begin{array}{c}\text { Size } \\
\left(\mathbf{m m}^{\mathbf{2}}\right)\end{array}$ & $\begin{array}{c}\text { Bandwidth } \\
(\mathbf{G H z})\end{array}$ & $\begin{array}{c}\text { Isolation } \\
(\mathbf{d B})\end{array}$ & $\begin{array}{c}\text { Power gain } \\
(\mathbf{d B})\end{array}$ \\
\hline$[\mathbf{1 8}]$ & $35 \times 40$ & $3.1-10.6$ & -16 & - \\
\hline$[\mathbf{1 9}]$ & $50 \times 30$ & $2.5-14.5$ & -20 & 7.4 \\
\hline$[\mathbf{2 0}]$ & $32 \times 32$ & $3.1-10.6$ & -15 & - \\
\hline$[\mathbf{2 1}]$ & $27 \times 28$ & $3-10.6$ & -16 & - \\
\hline Proposed & $20 \times 45$ & $2.97-19.82$ & -16 & 8.12 \\
\hline
\end{tabular}

\section{CONCLUSION}

A new compact $2 \times 2$ MIMO antenna system is proposed in this paper. The antenna system has been designed, simulated using an industrial standard simulation code, and optimized. The proposed ship-design MIMO system has s bandwidth of $16.85 \mathrm{GHz}$ ranging from $2.97 \mathrm{GHz}$ to $19.82 \mathrm{GHz}$ with $\mathrm{S} 12$ parameter less than $-16 \mathrm{~dB}$. The design is simple single layer and compact with total structure size of $20 \times 45 \times 1.6 \mathrm{~mm}^{3}$. The overall fractional bandwidth of the antenna was measured as $148.1 \%$. Also, the obtained peak gain value of the presented antenna system was measured as $8.12 \mathrm{~dB}$ with nearly omnidirectional radiation pattern.

\section{REFERENCES}

[1] I. Ndip, T. H. Le, O. Schwanitz, K. D. Lang, "A comparative analysis of 5G mmWave antenna arrays on different substrate technologies", 22nd International Microwave and Radar Conference, Poznan, Poland, May 14-17, 2018

[2] G. R. MacCartney, T. S. Rappaport, S. Sun, S. Deng, "Indoor office wideband millimeter-Wave propagation measurements and channel models at 28 and $73 \mathrm{GHz}$ for ultra-dense 5G wireless networks", IEEE Access, Vol. 3, pp. 2388-2424, 2015

[3] C. X. Mao, S. Gao, Y. Wang, "Broadband high-gain beam-scanning antenna array for millimeter-wave applications", IEEE Transactions on Antennas and Propagation, Vol. 65, No. 9, pp. 4864-4868, 2017

[4] H. Al-Saif, M. Usman, M. T. Chughtai, J. Nasir, "Compact ultra-wide band MIMO antenna system for lower 5G bands", Wireless Communications and Mobile Computing, Vol. 2018, Article ID 2396873, 2018

[5] Ofcom, Spectrum above $6 \mathrm{GHz}$ for future mobile communications, available at: https://www.ofcom.org.uk/_data/assets/pdf_file/0023/ 69422/spectrum_above_6_ghz_cfi.pdf, Ofcom, 2015

[6] 5G Americas, 5G Americas spectrum recommendations for the U.S., available at: https://www.5gamericas.org/wp-content/uploads/2019/07/ 5G Americas Spectrum Recommendations for the U.S Final.pdf, 5G Americas, 2018

[7] 5G Americas, Spectrum Landscape For Mobile Services, available at: https://www.5gamericas.org/wp-content/uploads/2019/07/5G_Americas _Whitepaper_Spectrum_Landscape_For_Mobile_Services_1.5.pdf, 5G $\bar{A}$ mericas, 2017

[8] ITU-R, Final Acts WRC-15, World Radiocommunication Conference, Geneva, ITU, 2015

[9] H. Alsaif, "Compact hexagonal monopole antenna for lower 5G bands", Engineering, Technology \& Applied Science Research, Vol. 9, No. 3, pp. 4200-4202, 2019

[10] M. Usman, R. A. Abd-Alhameed, P. S. Excell, "Design considerations of MIMO antennas for mobile phones", PIERS Online, Vol. 4, No. 1, pp. $121-125,2008$

[11] M. Dighriri, G. M. Lee, T. Baker, "Measurement and classification of smart systems data traffic over 5G mobile networks", in: Technology for Smart Futures, Springer, 2018

[12] S. Li, L. D. Xu, S. Zhao, "5G Internet of Things: A survey", Journal of Industrial Information Integration, Vol. 10, pp. 1-9, 2018

[13] Y. Wu, K. Ding, B. Zhang, J. Li, D. Wu, K. Wang, "Design of a compact UWB MIMO antenna without decoupling structure", International Journal of Antennas and Propagation, Vol. 2018, Article ID 9685029, 2018

[14] F. Wang, Z. Duan, S. Li, Z. L. Wang, Y. B. Gong, "Compact UWB MIMO antenna with meta-material-inspired isolator", Progress In Electromagnetics Research C, Vol. 84, pp. 61-74, 2018

[15] L. Wu, Y. Xia, X. Cao, Z. Xu, “A miniaturized UWB-MIMO antenna with quadruple band-notched characteristics", International Journal of Microwave and Wireless Technologies, Vol. 10, No. 8, pp. 948-955, 2018

[16] M. Matinmikko, M. Latva-aho, P. Ahokangas, V. Seppanen, "On regulations for 5G: Micro licensing for locally operated networks", Telecommunications Policy, Vol. 42, No. 8, pp. 622-635, 2018 
[17] R. Marsden, H. M. Ihle, "Mechanisms to incentivise shared-use of spectrum", Telecommunications Policy, Vol. 42, No. 4, pp. 315-322, 2018

[18] S. Zhang, Z. Ying, J. Xiong, S. He, "Ultrawideband MIMO/diversity antennas with a tree-like structure to enhance wideband isolation," IEEE Antennas and Wireless Propagation Letters, Vol. 8, pp. 1279-1282, 2009

[19] A. Iqbal, O. A. Saraereh, A. W. Ahmad, S. Bashir, "Mutual coupling reduction using F-shaped stubs in UWB-MIMO antenna”, IEEE Access, Vol. 6, pp. 2755-2759, 2018

[20] J. Ren, W. Hu, Y. Yin, R. Fan, "Compact printed MIMO antenna for UWB applications", IEEE Antennas and Wireless Propagation Letters, Vol. 13, pp. 1517-1520, 2014

[21] G. Srivastava, A. Mohan, "Compact dual-polarized UWB diversity antenna", Microwave and Optical Technology Letters, Vol. 57, pp. 2951-2955, 2015 